\title{
PREVALENCE OF CULTURE NEGATIVE ASCITIC FLUID INFECTION AMONG PATIENTS WITH CHRONIC LIVER DISEASE.
}

1. MBBS, MD (Gastroenterology) Assistant Professor

Gastroeneterology

DHQ Teaching Hospital Gujranwala Medical College

2. MBBS, MD (Gastroenterology) Doctor in Medical Endoscopy Suit DHQ Hospital, Sheikhupura.

3. MBBS, MD (Gastroenterology) Doctor in Medical Endoscopy Suit DHQ Hospital, Sheikhupura.

4. MBBS, FCPS (Medicine)

Doctor in Medical Endoscopy Suit DHQ DHQ Hospital, Sheikhupura.

Correspondence Address:

Dr. Muhammad Ayub

Department of Gastroeneterology

Gujranwala Medical College,

Gujranwala.

mnaich@hotmail.com

Article received on: 27/08/2019

Accepted for publication:

05/11/2019

\section{Muhammad Ayub', Sagheer Hussain ${ }^{2}$, Salman Ahmed ${ }^{3}$, Muhammad Adnan Iqbal ${ }^{4}$}

ABSTRACT... Objectives: To determine prevalence of patients with chronic liver disease having culture negative ascitic fluid infection. Study Design: Cross sectional study. Setting: Gastroenterology and medicine ward of DHQ Teaching Hospital Gujranwala. Period: January 2018 August 2018 having total duration of 8 months. Material \& Methods: All patients irrespective of age and gender, having ascites due to chronic liver disease and showing signs and symptoms of ascitic fluid infection like fever, abdominal pain and tenderness, admitted in the medical unit of study hospital underwent ascitic tap and fluid was sent for culture examination to the hospital laboratory. Patients with chronic liver disease having no bacterial growth found on culture of ascitic fluid were placed in one group and who had culture positive ascites were placed in separate group. Patients who have taken any antibiotic in last one month or having any intra abdominal source of infection were excluded from the study. All cases in study group were already diagnosed with CLD. Results: There were 160 cases included in this study having chronic liver disease and ascitic fluid infection with $62.5 \%$ male and $37.5 \%$ female cases. Out of 160 cases, $22.5 \%$ were having culture positive ascites while $77.5 \%$ cases were having culture negative ascites among them $61 \%$ were male and $39 \%$ were female in positive group and $62.9 \%$ were male and $37.1 \%$ were female cases in negative group. Age range of patients was $25-75$ years with mean age of $50 \pm 25$ years. Mean duration of chronic liver disease was $9.5 \pm 2.4$ months with minimum duration of 6 months and maximum duration of 15 months. There were $72.6 \%$ cases with culture negative ascites and $69.4 \%$ with positive culture were having age above 45 years. There was majority of male patients $(62.9 \%)$ having culture negative ascites due to CLD. Conclusion: Ascitic fluid infection among patients with chronic liver disease is usually culture negative. In our study prevalence of culture negative ascitic flud infection was $77.5 \%$, more common among male patients having age above 45 years.

Key words: $\quad$ Ascitic Fluid Infection, Ascitic Tap, Chronic Liver Disease, Portal Hypertension.

Article Citation: Ayub M, Hussain S, Ahmed S, lqbal MA. Prevalence of culture negative ascitic fluid infection among patients with chronic liver disease. Professional Med J 2020; 27(5):999-1003. DOI: 10.29309/TPMJ/2020.27.05.4074

\section{INTRODUCTION}

Chronic liver disease is a very common disease in our community with high prevalence rate with high mortality rate. This disease leads to liver cirrhosis and portal hypertension producing typical signs and symptoms of upper gastrointestinal bleeding, hemorrhoids, and abdominal ascites. In liver cirrhosis scars and nodules are formed in liver parenchyma. Liver plays many roles in body but major role is detoxification and removal of bacteria from blood. Therefore in liver failure bactiremia and various bacterial infections occur. ${ }^{1}$

Ascites is defined as abnormal fluid collection in abdominal cavity. It occurs in $60 \%$ of cases with compensated liver failure within 10 years after diagnosing the disease. Mortality rate is $40 \%$ in a year and $50 \%$ within 2 years. Patients having refractory ascites usually do not survive more than 6 months. Patients with ascites after liver cirrhosis have findings of hyponatremia, low urine sodium, ascitic fluid low protein content $\leq 2 \mathrm{~g} / \mathrm{dl}$ and spontaneous bacterial peritonitis. ${ }^{2}$

Other complications of chronic liver disease include encephalopathy, hepatorenal syndrome, hepatopulmonary syndrome, coagulopathy and hepatocellular carcinoma. Development of a bacterial infection in the peritoneum in the absence of obvious source of infection is called 
spontaneous bacterial peritonitis (SBP). A model of end stage liver disease (MELD) score is very useful in predicting development of spontaneous bacterial peritonitis in future so this condition can be prevented in time and managed promptly using this scoring system. ${ }^{3}$

Albumin is a major blood protein maintaining oncotic pressure. In CLD total protein content of blood is decreased. Due to low oncotic pressure fluid from vessels comes out in peritoneal space and collects producing ascites. For treating ascites albumin is transfused to the patient to increase oncotic pressure in blood vessels. ${ }^{4}$

Enterobacter and Streptococci are most common bacteria causing spontaneous bacterial peritonitis in patients with chronic liver disease. ${ }^{5}$

Ascitic fluid infection is classified into three types spontaneous bacterial peritonitis, culture negative neutrocytic ascites (CNNA) and non-microbial non neutrocytic bacterascites (MNBA). Recent studies do not differentiate between SBP and CNNA for treatment purpose and recommend that if polymorphonuclear count is more than 250 cells $/ \mathrm{mm}^{3}$ immediate antibiotic treatment should be given and should not wait for bacterial culture report. $^{6}$

In this study we studied culture negative neutrocytic ascites in patients with chronic liver disease. In spontaneous bacterial peritonitis antibiotics should be given according to the culture and sensitivity report of ascitic fluid otherwise antibiotic resistance is developed in patients and basic infection is not cured due to wrong antibiotic therapy. ${ }^{7,8}$

\section{MATERIAL \& METHODS}

First of all approval was taken from ethical committee of the study institution DHQ Teaching Hospital Gujranwala for conducting study in the hospital. Study was conducted in gastroenterology and medical wards of the hospital. A performa was designed in which all relevan data of each patient was documented such as name, age, address, duration of CLD, important points of history like previous treatment, history of previously done ascitic tap or taking any antibiotic therapy and important points of physical examination.

There were 160 patients included in our study which were falling in our inclusion criteria. Patients having chronic liver disease as a cause of ascites and showing signs and symptoms of ascitic fluid infection like fever, abdominal pain and tenderness, respiratory distress without any intra abdominal source of infection were included in this study. These cases were not underwent ascitic tap previously.

All other patients having cause of ascites other than liver cirrhosis, having tuberculous peritonitis any intraabdominal source of infection or tuberculosis, pancreatitis, secondary peritonitis or malignancy or who had taken antibiotic therapy in last one month were not included in this study. Patients having ascitic flyid infection were divided into two groups one consisted on all cases with positive culture of ascitic fluid and other group having culture negative ascitic fluid infection. Diagnostic peritoneal tap was done using 20cc sterile syringe, $20 \mathrm{ml}$ of ascitic fluid taken put into EDTA tube and examined within 3 hours. Total leucocyte count and differential leucocyte count and total protein content in sample was determined in laboratory.

Culture and sensitivity of ascitic fluid was also determined for each sample. Statistical analysis of data was done using SPSS software (version 25). Results were calculated in the form of percentages for qualitative data and means and standard deviation for quantitative data. P-value less than 0.05 was considered significant. Results were presented in tabular and graphical forms.

\section{RESULTS}

There were total 160 patients in this study having clinically ascitic fluid infection. There were 100() male and 60() female cases. Out of total 160 cases 124() cases including 78() male and 46() female cases were having culture negative ascites and 36() patients including 22() male and 14() female patients were having culture positive ascites (Table-I). 
Age range of patients was 25-75 years with mean age of $50 \pm 25$ years. There were 12() cases between 25-35 years, 23() between 36-45 years, 35() between 46-55 years, 54() between 56-65 years and 36 patients were having age 66-75 years (Table-II).

Among patients with culture negative ascites $34(27.4 \%)$ cases were having age less than 45 years and $90(72.6 \%)$ having age above 45 years and out of those having culture positive ascites $11(30.6 \%)$ cases were having age below 45 years and $25(69.4 \%)$ above 45 years of age (Table-III).

Duration of chronic liver disease among cases having culture negative ascites was less than 6 months in $40(32.2 \%)$ cases and more than 6 months in $84(67.7 \%)$ cases, among cases with culture positive ascites duration of CLD was less than 6 months in 56(35\%) cases and more than 6 months in 104(65\%) cases (Table-IV).

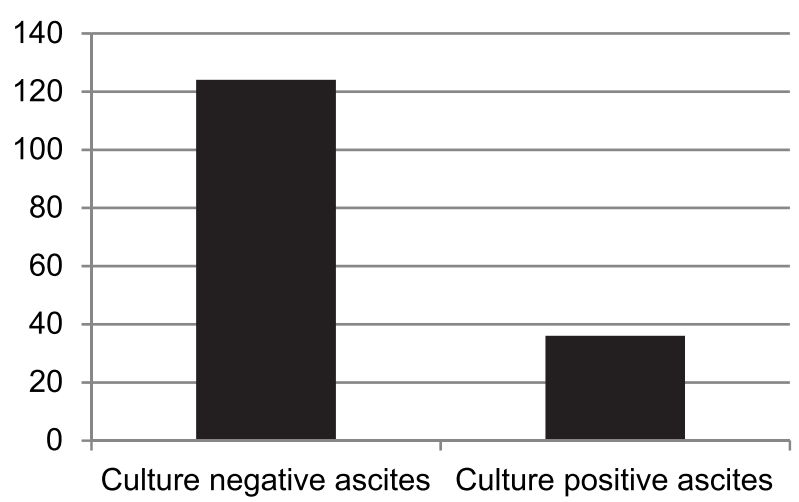

Figure-1. Frequency of culture positive and culture negative ascites in study group $(n=160)$

\begin{tabular}{|l|c|c|c|c|}
\hline \multicolumn{1}{|c|}{ Gender } & $\begin{array}{c}\text { Culture Negative } \\
\text { Ascites }\end{array}$ & $\begin{array}{c}\text { Culture Positive } \\
\text { Ascites }\end{array}$ & Total & P-Value \\
\hline Male & $78(62.9 \%)$ & $22(61.1 \%)$ & $100(62.5 \%)$ & 0.542 \\
\hline Female & $46(37.1 \%)$ & $14(38.9 \%)$ & $60(37.5 \%)$ & 0.812 \\
\hline Total & $124(100 \%)$ & $36(100 \%)$ & $160(100 \%)$ & \\
\hline
\end{tabular}

\begin{tabular}{|l|c|c|c|}
\hline \multicolumn{1}{|c|}{ Age (years) } & Male & Female & \multicolumn{1}{c|}{ Total } \\
\hline $25-35$ & 8 & 4 & $12(7.5 \%)$ \\
\hline $36-45$ & 16 & 7 & $23(14.4 \%)$ \\
\hline $46-55$ & 20 & 15 & $35(21.9 \%)$ \\
\hline $56-65$ & 25 & 29 & $54(33.8 \%)$ \\
\hline $66-75$ & 20 & 16 & $35(21.9 \%)$ \\
\hline Total & 100 & 60 & $160(100 \%)$ \\
\hline
\end{tabular}

Table-II. Age distribution of cases in study group $(n=160)$

\begin{tabular}{|l|c|c|c|c|}
\hline \multicolumn{1}{|c|}{ Age (Years) } & $\begin{array}{c}\text { Culture Negative } \\
\text { Ascites }\end{array}$ & $\begin{array}{c}\text { Culture Positive } \\
\text { Ascites }\end{array}$ & Total & P-Value \\
\hline$<45$ & $34(27.4 \%)$ & $11(30.6 \%)$ & $100(62.5 \%)$ & 0.992 \\
\hline$>45$ & $90(72.6 \%)$ & $25(69.4 \%)$ & $60(37.5 \%)$ & 0.732 \\
\hline Total & $124(100 \%)$ & $36(100 \%)$ & $160(100 \%)$ & \\
\hline
\end{tabular}

Table-III. Comparison of age among patients having culture positive and negative ascites in study group

\begin{tabular}{|l|c|c|c|c|}
\hline \multicolumn{1}{|c|}{$\begin{array}{c}\text { Duration of CLD } \\
\text { (months) }\end{array}$} & $\begin{array}{c}\text { Culture Negative } \\
\text { Ascites }\end{array}$ & $\begin{array}{c}\text { Culture Positive } \\
\text { Ascites }\end{array}$ & Total & P-Value \\
\hline$<6$ & $40(32.2 \%)$ & $16(44.4 \%)$ & $56(35 \%)$ & 0.856 \\
\hline$>6$ & $84(67.7 \%)$ & $20(55.5 \%)$ & $104(65 \%)$ & 0.664 \\
\hline Total & $124(100 \%)$ & $36(100 \%)$ & $160(100 \%)$ & \\
\hline
\end{tabular}

Table-IV. Comparison of duration of CLD among patients with culture positive and negative ascites 


\section{DISCUSSION}

Bacterial infections in patients with liver cirrhosis are main threat of developing spontaneous bacterial peritonitis (SBP). It is associated with high mortality rate in patients with liver cirrhosis even after resolution of SBP, life expectance was not good in such chronically ill patients. Patients with decompensated liver cirrhosis have weak immune system so making them susceptible to various infections particularly SBP which leads to development of hepatic encephalopathy, upper GIT bleeding and acute kidney injury. If SBP is acquired in hospitals (Nosocomial SBP) then mortality rate is very high up to $30 \% .^{9,10}$ A study conducted in Nepal on 81 cases out of them $20(24.7 \%)$ cases were having SBP comprising on its variants, $65 \%$ cases with CNNA, $20 \%$ having classical SBP and 15\% having bacterascites. ${ }^{11}$ In our study 160 cases were included having SBP and out of them Culture negative SBP was present in 124(77.5\%) cases and culture positive SBP was found in $22.5 \%$ cases.

A study conducted in Karachi, a city of Pakistan, reported culture positive SBP in $21.5 \%$ while culture negative SBP was present in $78.5 \%$ cases. Patients having culture negative SBP were consisted of $54.7 \%$ male and $45.2 \%$ female cases. Age range in their study was $18-67$ years. ${ }^{12}$ This is compared to our study in which age range was 25-75 years and cases with culture negative ascites were consisted of $62.9 \%$ and $37.1 \%$. To prevent ascitic fluid infection after ascitic tap first line antibiotic therapy should be given to the patients immediately. Children having ascites are more prone to get ascitic fluid infection therefore special care should be given to children and if there is no signs and symptoms of ascitic fluid infection then ascitic tap should be avoided to prevent development of nosocomial peritonitis. ${ }^{13,14}$

Diagnosis of spontaneous bacterial peritonitis is made by culture of ascitic fluid but sometimes culture is negative inspite of ascitic fluid infection and increased neutrophil count in ascitic fluid so culture alone is not sufficient to diagnose SBP hence a study conducted in Egypt studied Amyloid-A in serum and ascitic fluid as a diagnostic marker for SBP. They reported sensitivity and specificity $90 \%$ and $60 \%$ respectively of ascitic fluid Amyloid-A level for diagnosing SBP. Serum Amyloid-A level has high sensitivity and specificity than ascitic fluid level. ${ }^{15}$ A study conducted on patients having culture negative neutrocytic ascites mentioned that it is a variant of SBP and having mortality rate same as SBP. The term culture negative neutrocytic ascites was used in 1984 by Runyon and it is described as increased neutrophil count in ascitic fluid greater than 250 cells $/ \mathrm{mm}^{3}$, negative ascitic fluid culture and absence of antibiotic therapy in last one month, no intra abdominal source of infection which can be treated surgically or pancreatitis. ${ }^{16} \mathrm{~A}$ study conducted in Korea concluded that patients with SBP were having high MELD score, higher rate of positive culture of ascitic fluid and also higher 7-days mortality rate as compared to patients having culture negative neutrocytic ascites (CNNA), while 30-days and 90-days mortality rate was equal in both groups. According to their study prevalence of SBP was $48.6 \%$ and CNNA was $51.4 \% .^{17}$

\section{CONCLUSION}

Our study concluded that most of the patients presenting to teaching hospitals in our community with ascites due to liver cirrhosis have culture negative ascites while they have clinically ascitic fluid infection. So patients showing clinically infection of ascitic fluid should be treated with empirical antibiotics immediately without waiting for culture report. In our study ascitic fluid infection was mostly seen in male patients and patients having age above 45 years and duration of CLD more than 6 months. Early diagnosis of the disease and immediate treatment can reduce morbidity and mortality rate.

Copyright $(05$ Nov, 2019.

\section{REFERENCES}

1. Bilal F, Arain MI. Utilization of antimicrobial agents for prophylaxis and treatment of bacterial infection in liver diseases and its complications. Rawal Medical Journal. 2019; 44(3):445-8.

2. Garbuzenko DV, Arefyev NO. Current approaches to the management of patients with cirrhotic ascites. World Journal of Gastroenterology. 2019 Jul 28; 25(28):3738. 
3. Khan R, Ravi S, Chirapongsathorn S, Jennings W, Salameh H, Russ K, Skinner M, Mudumbi S, Simonetto D, Kuo YF, Kamath PS. Model for End-Stage Liver Disease Score Predicts Development of First Episode of Spontaneous Bacterial Peritonitis in Patients With Cirrhosis. InMayo Clinic Proceedings 2019 Sep 1 (Vol. 94, No. 9, pp. 1799-1806). Elsevier.

4. Fernández J, Angeli P, Trebicka J, Merli M, Gustot T, Alessandria C, Aagaard NK, De Gottardi A, Welzel TM, Gerbes A, Soriano G. Efficacy of albumin treatment for patients with cirrhosis and infections unrelated to spontaneous bacterial peritonitis. Clinical gastroenterology and hepatology. 2019 Aug 5.

5. Huang D, Zhao Y, Jiang Y, Li Z, Yang W, Chen G. Spontaneous bacterial peritonitis caused by Aeromonas caviae in a patient with cirrhosis. Zhong nan da xue xue bao. Yi xue ban= Journal of Central South University. Medical sciences. 2015 Mar; 40(3):341-4.

6. Srivastava A, Malik R, Bolia R, Yachha SK, Poddar U. Prevalence, clinical profile, and outcome of ascitic fluid infection in children with liver disease. Journal of pediatric gastroenterology and nutrition. 2017 Feb 1; 64(2):194-9.

7. Bibi S, Ahmed W, Arif A, Khan F, Alam SE. Clinical, laboratory and bacterial profile of spontaneous bacterial peritonitis in chronic liver disease patients. J Coll Physicians Surg Pak. 2015 Feb 1; 25(2):95-.

8. Singh SK, Poddar U, Mishra R, Srivastava A, Yachha SK. Ascitic fluid infection in children with liver disease: time to change empirical antibiotic policy. Hepatology international. 2019 Jul 9:1-7.

9. Kimmann $M$, Tergast TL, Schultalbers $M$, Laser H, Gerbel S, Manns MP, Cornberg M, Maasoumy B. Sustained impact of nosocomial-acquired spontaneous bacterial peritonitis in different stages of decompensated liver cirrhosis. PloS one. 2019 Aug 2; 14(8):e0220666.
10. Elfotouh Ibrahim AA, Hussein A, Salah M, Zakarya Shady ZM, Metwally M, Mohammed M, Amer M, Saad A. Use of fecal calprotectin as a predictor of spontaneous bacterial peritonitis in post hepatitis c cirrhotic Egyptian patients. Egyptian Journal of Hospital Medicine. 2019 Jul 5; 76(3).

11. Ithape A, Mahashabde M, Nikam AA, Edge H. A study of biochemical and microbiological findings of spontaneous bacterial peritonitis (SBP) in liver cirrhosis. International Journal of Scientific Research. 2019 Jul 18; 8(4).

12. Jafri S, Awan $\mathrm{RH}$, Nayab S, Awan KH. Spontaneous bacterial peritonitis; frequency of culture positive (SBP) and culture negative spontaneous bacterial peritonitis (Neutrocytic Ascites) in cirrhotic population. Professional Medical Journal. 2019 Mar 1; 26(3).

13. Ghobrial C, Mogahed EA, El-Karaksy H. Routine analysis of ascitic fluid for evidence of infection in children with chronic liver disease: Is it mandatory?. PloS one. 2018 Oct 5; 13(10):e0203808.

14. Bal C. PE-184: Predictors of fifty days in-hospital mortality in patients with CNNA. (KASL). 2018; 2018(1):219-.

15. Badawi R, Asghar MN, Abd-Elsalam S, Elshweikh SA, Haydara T, Alnabawy SM, Elkadeem M, ElKhalawany W, Soliman S, Elkhouly R, Watany M. Amyloid A in Serum and Ascitic Fluid as a Novel Diagnostic Marker of Spontaneous Bacterial Peritonitis. Anti-inflammatory \& Anti-allergy Agents in Medicinal Chemistry. 2019 Apr 1.

16. Bal CK, Bhatia V, Daman R. Predictors of fifty days inhospital mortality in patients with culture negative neutrocytic ascites. BMC gastroenterology. 2017 Dec; $17(1): 64$.

17. Na SH, Kim EJ, Nam EY, Song KH, Choe PG, Park WB, Bang JH, Kim ES, Park SW, Kim HB, Oh MD. Comparison of clinical characteristics and outcomes of spontaneous bacterial peritonitis and culture negative neutrocytic ascites. Scandinavian journal of gastroenterology. 2017 Feb 1; 52(2):199-203.

\begin{tabular}{|c|l|l|l|}
\hline \multicolumn{3}{|c|}{ AUTHORSHIP AND CONTRIBUTION DECLARATION } \\
\hline Sr. \# & \multicolumn{1}{|c|}{ Author(s) Full Name } & \multicolumn{1}{|c|}{ Contribution to the paper } & Author(s) Signature \\
\hline 1 & Muhammad Ayub & $\begin{array}{l}\text { Topic selection and data } \\
\text { collection. } \\
\text { Data analysis, Data collection. }\end{array}$ \\
\hline 2 & Sagheer Hussain & $\begin{array}{l}\text { Found additional literature for } \\
\text { information, Data composing. }\end{array}$ \\
\hline 3 & Salman Ahmed & Muhammad Adnan lqbal & Abstract and recording. \\
\hline
\end{tabular}

